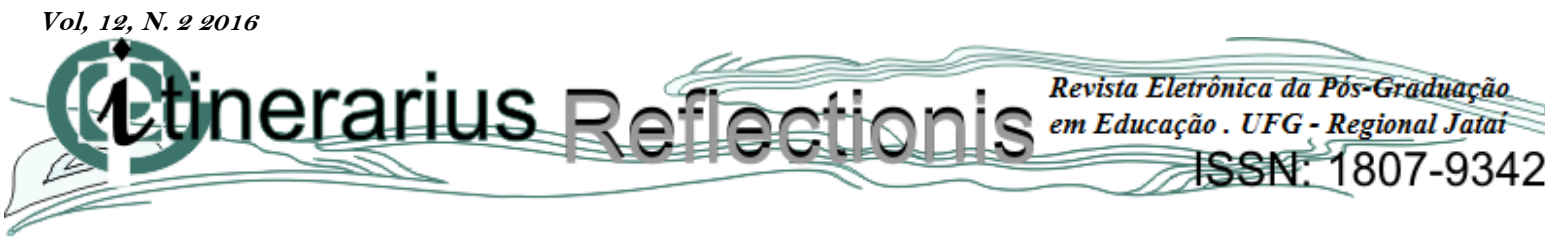

\title{
POSSIBILIDADES DA PSICOLOGIA NO ENSINO MÉDIO: UMA PROPOSTA DE ORIENTAÇÃO PROFISSIONAL
}

\author{
Tatiely Pereira de Araújo
}

Jessica Larissa Ferrari Becker

\begin{abstract}
RESUMO: Este trabalho refere-se a um subprojeto do Programa Institucional de Bolsa de Iniciação à Docência Pibid, do curso de Psicologia da Universidade Federal de Goiás, Campus Goiânia. O projeto de Orientação Profissional, baseado na abordagem históricocultural, foi realizado em um Colégio Estadual de Ensino Médio de Goiânia, na disciplina Projeto de Vida. Tivemos como objetivo desenvolver debates e provocar reflexões nos alunos a respeito dos processos relacionados à escolha profissional. Para alcançar este objetivo o projeto foi desenvolvido em três unidades: módulo 1 - Autoconhecimento e o Significado da Escolha Profissional; módulo 2 - Os Determinantes da Escolha Profissional; módulo 3 Informação Profissional. As aulas foram ministradas em quatro turmas de alunos dos segundos anos uma vez por semana, 50 minutos por aula. A metodologia mais utilizada foi de aula expositiva-dialogada, embora tenha havido também projeção do filme "Divergente", músicas e vídeos. Ao final da realização do projeto, acreditamos que a experiência foi formativa, pois foi possível perceber a mudança nos paradigmas através da fala dos próprios alunos: passaram a analisar as multideterminações envolvidas em um processo de escolha; conhecer mais e melhor diversas profissões e o percurso necessário para se chegar até ela, etc. Para nós licenciados, a experiência também se mostrou bastante formativa, pois permitiu a aproximação do aluno de Psicologia com o Ensino Médio. Portanto, nos fez repensar criticamente as contribuições que a Psicologia poderia oferecer a essa etapa da educação básica, caso fosse inserida no currículo das escolas de Ensino Médio.
\end{abstract}

Palavras-chave: Orientação Profissional, Ensino Médio, Psicologia, Pibid.

\section{POSSIBILITIES OF PSYCHOLOGY IN HIGH SCHOOL: A PROPOSAL FOR VOCATIONAL ORIENTATION}

ABSTRACT: This paper refers to a subproject of the Institutional Program Initiation to Teaching Exchange (Pibid), the Psychology course at the Federal University of Goiás, Goiânia campus. The design of Vocational Guidance, based on cultural-historical approach, was conducted in a State College High School in Goiânia, in the discipline of Project Life. Our aim was to provoke thoughts and discussions to develop in students about the processes related to vocational choice. To achieve this goal the project was developed in three units: Module 1 - Self-knowledge and the Meaning of Career Choice; Module 2 - The Determinants of Vocational Choice; Module 3 - Professional Information. Classes were taught in four classes of second year students once a week, 50 minutes per class. The most common method used was expository-dialogic class, although there has also been screening of the film "Divergent", music and videos. Following the conclusion of the project, we believe that the 
experience was very worthwhile because it was possible to notice a change in the paradigms through speech from the students themselves: now analyze multideterminações involved in a process of choice; more and better meet diverse professions and the route taken to get to it, etc. Licensed to us, the experience also proved very formative because it allowed the approaching student of Psychology in Secondary Education. Therefore made us rethink critically the contributions that psychology could offer this stage of basic education, if it was inserted in the curriculum of secondary schools.

Keywords: Career Counseling, Secondary Education, Psychology, Pibid.

\section{INTRODUÇÃO}

O Programa Institucional de Bolsa de Iniciação à Docência (Pibid) é uma iniciativa da Capes que visa valorizar a formação dos professores, consequentemente objetiva à melhoria da qualidade do ensino básico e está direcionado às Instituições de Ensino Superior que oferecem cursos de licenciatura. Por meio deste projeto, nós licenciandos somos inseridos no cotidiano das escolas parceiras da rede pública de educação, o que oportuniza criar e participar de experiências metodológicas, tecnológicas e práticas docentes que contribuem para nossa formação profissional e pessoal.

O Pibid na Psicologia, em particular, possibilita não apenas a inserção dos alunos em contextos educativos, como ainda refletir a inserção desta ciência na educação, tanto formal como não formal. Essa dimensão, contudo, é fomentada na discussão a respeito do ensino de Psicologia, a partir das novas Diretrizes Curriculares Nacionais para os cursos de Graduação de Psicologia (2011), em que se estabelece a obrigatoriedade da oferta da licenciatura, recolocando de forma imperativa a necessidade de se pensar as contribuições das temáticas da Psicologia na educação básica pública brasileira.

Entre os desdobramentos da discussão a respeito da formação do professor de Psicologia, se encontra a possibilidade de um campo de atuação a partir do projeto de Lei proposto pela deputada federal Luiza Erundina do PSB/SP (PL 105/2007), em defesa da inserção da disciplina de Psicologia no Ensino Médio. Proposta defendida pela Associação Brasileira do Ensino de Psicologia (ABEP), em parceria com a Associação Brasileira de Psicologia Escolar e Educacional (ABRAPEE), com o Conselho Federal de Psicologia (CFP) e também com o Fórum de Entidades Nacionais de Psicólogos Brasileiros (FENPB), que lançaram em meados de 2008 a campanha Oito Razões para aprender Psicologia no ensino médio. Tal reivindicação expressa tensões e contradições inerentes ao processo de constituição da psicologia da educação no Brasil (ANTUNES, 2000) e provoca a problematização a respeito tanto desse campo de atuação como da formação desse professor. 
O projeto, ao possibilitar a inserção do aluno de Psicologia como professor no Ensino Médio, ofereceu condições para se repensarem criticamente as contribuições que a Psicologia poderia oferecer a essa etapa da educação básica, que vem sendo defendida por diversas associações. Como o currículo escolar para o Ensino Médio não apresenta a disciplina de Psicologia, a equipe envolvida criou espaços de atuação na escola parceira.

O trabalho foi realizado em uma Escola Estadual de Ensino Médio, em uma disciplina denominada "Projeto de Vida", que ocorre uma vez por semana, em uma aula de 50 minutos. A disciplina foi escolhida a partir da diagnose da instituição, e por meio de um diálogo com o campo e com os professores, em que se constataram dificuldades nas questões referentes à escolha profissional e as várias instâncias que contribuem para tal preferência. Uma vez que estas influências são internalizadas de maneira singular por cada aluno.

Neste artigo será discutido os pressupostos teóricos que orientaram a intervenção feita no contexto escolar, bem como foi operacionalizado todo o projeto a partir da contextualização do ambiente escolar e dos objetivos e metodologias pensados para realiza-lo. Ao fim, será apresentado uma breve discussão dos resultados alcançados apontando para os desafios, limites e possibilidades que este projeto apresentou na efetivação de sua prática. Para além disso, será apontado algumas questões para discutir a respeito do papel da psicologia no Ensino Médio.

\section{REFERENCIAL TEÓRICO}

A questão da escolha de uma profissão ou ocupação não se dá como um problema universal da espécie humana ao longo da história da humanidade. Identifica-se que esta questão, "o que fazer para alcançar a sobrevivência”, se faz presente ao longo da história, mas só recentemente que se passa a problematizá-la (ABADE, 2005). Por muito tempo, esta questão apresentava-se de forma natural, como nos ancestrais em que não há muita diferenciação de funções a não ser pelo sexo, ou até mesmo na idade média em que a sociedade estratificada não dispunha de espaços para remeter esta discussão aos indivíduos. Neste período o conceito de vocação é apresentado, mas somente no âmbito religioso como um chamado divino que impõe uma missão para os indivíduos (BOCK, 2006).

Entretanto, recentemente o conceito de vocação muda com o advento do capitalismo e da constituição da burguesia, que passa a pregar o valor da igualdade entre os homens. Para justificar as diferenças encontradas na sociedade, desenvolve-se o conceito de vocação que 
passa agora a se restringir somente o âmbito biológico, atribuindo à causa orgânica as diferenças individuais e sociais. Assim, o ser humano nasce com atributos específicos que localizam o indivíduo na estrutura da sociedade da mesma forma que serve para justificar seu fracasso (LISBOA, 2000).

De acordo com Bock (2006), há várias teorias que discutem a orientação profissional a partir de vários enfoques diferentes. Mas, é possível identificar atualmente uma nova forma de organização destas teorias a partir da concepção de indivíduo e sociedade que possuem. A primeira delas, teorias tradicionais (abordagem liberal), defende o que pode ser chamado de "modelo de perfil". Este modelo pressupõe que uma boa escolha é aquela que relaciona harmoniosamente um perfil profissional ou ocupacional e o perfil pessoal, delineado a partir de qualquer técnica ou instrumento. A escolha da profissão resume em uma atividade de comparação. Logo, a função do orientador profissional seria ajudar o indivíduo a conscientizar de suas características pessoais que seguem um modelo estático, ou seja, defende que as pessoas não mudam muito a partir do fim da adolescência. Neste sentido, é possível reconhecer que todas as teorias psicológicas apoiam-se de certa maneira neste modelo de perfil (LEVENFUS; SOARES, 2000).

Para Ferreti $(1988,1997)$, cada teoria que busca identificar a melhor forma da escolha profissional possui um aspecto ideológico contido na questão. Para estas teorias psicológicas, pode-se identificar quatro aspectos centrais da concepção de indivíduo e sociedade que dão sustentação a esta ideia. A primeira, diz que estas se propõem a explicar como o indivíduo processa a sua escolha bem como o seu resultado. A segunda defende que a escolha é um uma decisão pessoal e individual. A terceira admite que fatores sociais e individuais interfiram no processo, mas defende o caráter biopsicológico dos seres humanos, compreendendo que os aspectos sociais são limitadores ou castradores das características originais e da essência do indivíduo. Por último, que os indivíduos se diferem por uma série de atributos que os levarão a optar por diferentes caminhos profissionais. Logo, compreende-se que nesta visão liberal, o indivíduo tem a possibilidade de ultrapassar os obstáculos colocados pela realidade, e esta escolha se for adequada, asseguraria melhor condição de vida. Assim, o principal e único determinante para o sucesso e fracasso do indivíduo é o próprio indivíduo (BOCK, 2006).

De acordo com Sparta (2003), outra classificação que se pode identificar são as chamadas teorias críticas surgidas no Brasil na década de 1970 e início de 1980. Estas teorias têm por objetivo examinar as teorias tradicionais, liberais apontando seu caráter ideológico. 
Para Ferreti (1988), é possível constatar que a sociedade não oferece reais condições de igualdade, que não há liberdade de escolhas e que a individualidade compreendida por talentos, aptidões e habilidades também é questionável. Logo, as opções e escolhas inadequadas feitas são de responsabilidade individual, questões como "liberdade de escolha", "por que e para que decidir" não são questionadas.

Esta perspectiva critica a ação ideológica das teorias tradicionais e intervém com a função de dissimular a realidade, ao esconder os determinantes econômicos, políticos e sociais do fenômeno e isolar apenas o individual como essencial. Assim, é na estrutura social e econômica que explica o posicionamento da pessoa na sociedade, o indivíduo não tem autonomia para definir seu caminhar e constitui-se como reflexo da sociedade. Entretanto, Lisboa (2000), identifica que ao negar a existência de liberdade de escolha, acaba por também negar a existência do indivíduo, pois este passa a ser entendido como reflexo da organização social, não possuindo autonomia frente a tais determinações.

A partir disto, a nova abordagem criada por Bock (2006) pode ser denominada como uma abordagem sócio-histórica, pois se classifica como uma teoria para além da crítica, objetivando superar a dicotomia entre o indivíduo e a sociedade apresentando uma forma dialética de relacionar estes dois conceitos. Da mesma forma que as teorias críticas, a abordagem sócio-histórica entende que o ser humano é multideterminado. Compreende-se que o indivíduo é e não é ao mesmo tempo reflexo da sociedade, assim como é e não é autônomo em relação a ela. Aqui, abre-se a possibilidade de mudança, de alteração histórica ao reconhecer que os indivíduos podem de alguma maneira intervir sobre as condições sociais por meio de ações pessoais e coletivas.

Para Vigotsky (1991), a cultura torna parte da espécie humana em um processo histórico ao longo do desenvolvimento da espécie e do indivíduo, formando o funcionamento psicológico do homem. É possível identificar que não há embate entre indivíduo e sociedade, mas sim uma personalidade social que resulta da internalização do que é social. Da mesma forma, o conceito de identidade é compreendido a partir da forma que cada indivíduo absorve para si as relações sociais, fomentando uma identidade pessoal. A identidade como metamorfose é o que vai basear o entendimento da escolha profissional nesta abordagem.

Assim, é possível identificar alguns pontos que definem a abordagem sócio-histórica, como: a defesa da não existência da natureza humana, mas sim condição humana que é compreendida como condições biológicas hereditárias que dá sustentação para um 
desenvolvimento sócio-histórico; o homem é concebido como um ser ativo, social e histórico, o que lhe dá a característica social; o homem é criado pelo próprio homem, é a partir das relações sociais mediadas pela linguagem que o homem adquire consciência; e por último, que é o homem concreto o objeto de estudo da psicologia, pois este só pode ser compreendido em sua singularidade imerso na totalidade histórica e social em que vive (BOCK, 1999).

Sendo assim, na abordagem sócio-histórica, o conceito de vocação é entendido da seguinte maneira: "a vocação do ser humano é exatamente não ter outras vocações" pois, ele não possui nada em seu corpo que o obrigue a realizar determinada tarefa. Desta forma, BOCK (2006) prevê que a função da orientação profissional nesta perspectiva é para a promoção de saúde, superando o conceito de prevenção que tem como referência a patologia na qual deveria ser prevenida.

\section{DESCRIÇÃO DO CONTEXTO}

O Projeto de Orientação Profissional acontece em um Colégio Estadual localizado setor Leste Universitário, da cidade de Goiânia (GO), localizado em uma região privilegiada na qual existe um grande número de universidades. A instituição oferece educação pública em período integral a alunos da $1^{\mathrm{a}}$ a $3^{\mathrm{a}}$ série do Ensino Médio, atendendo a uma população estudantil em uma faixa etária de 14 a 17 anos, sem limite de idade. Os alunos são oriundos de vários bairros da cidade de Goiânia, bem como de outras cidades da região metropolitana: Senador Canedo, Trindade, Aparecida de Goiânia, Bonfinópolis, etc.; situados em um nível sócio-econômico de classe média à classe média baixa (PPP, 2014).

A instituição em questão é resultado da junção de outras duas antigas unidades de ensino. A união se deu porque, em 2003, um deles passou por uma crise que provocou esvaziamento de alunos e perda da credibilidade frente à comunidade; o outro, por sua vez, tinha uma estrutura física muito pequena que não comportava o número de seus alunos. Diante dessa realidade, a Secretaria Estadual de Educação decidiu por unir as duas escolas. Assim, a junção foi feita, e aproveitando os professores, funcionários, alunos e direção de ambas as instituições, (sob a forma da Lei de nova denominação de Ensino $n^{\circ}$ 15.219, de 23 de junho de 2005; publicada no Diário Oficial, ano 168 - Diário Oficial/GO - n 19670) (PPP, 2014).

A partir de nossas observações, foi possível notar que o colégio dispõe de amplo espaço; trata-se de uma unidade de ensino com grande estrutura física, porém as instalações se 
encontram em precário estado de conservação. As salas de aula são quentes, escuras e mal ventiladas. A insituição dispõe de sala de laboratório de informática, laboratório de química e física, biblioteca, sala de professores, 22 banheiros, 22 salas de aula, secretaria, coordenação, cozinha, espaço para convivência (pátio), uma quadra de esporte aberta uma quadra de esporte coberta (PPP, 2014).

O Projeto de Orientação Profissional é realizado em quatro turmas de $2^{\circ}$ ano do Ensino Médio ( $2^{\circ}$ ano A, B, C e D), tendo cada turma dois acadêmicos de Licenciatura em Psicologia como responsáveis pelas aulas. O Projeto de Orientação Profissional foi desenvolvido na disciplina de "Projeto de Vida", a qual tem por objetivo desenvolver pessoal e socialmente o jovem, levando-o a planejar, estruturar e realizar seus sonhos na forma de um plano concreto (Apostila das aulas do Projeto de Vida, s/d). Entendendo a carreira profissional como um dos eventos da vida sobre o qual os jovens constroem sonhos e elaboram projetos, o Projeto de Orientação Profissional viu nessa disciplina espaço e oportunidade para trabalhar questões referentes à escolha profissional de adolescentes.

Este trabalho teve como objetivo geral, desenvolver debates e provocar reflexões a respeito dos processos relacionados à escolha profissional. Os objetivos específicos, por sua vez, foram: identificar as impressões e o conhecimento dos alunos acerca da escolha profissional; promover debates e discussões em grupo a respeito da orientação profissional e das implicações desta escolha na vida dos alunos; e contribuir para o maior conhecimento sobre as diferentes áreas de atuação profissional. Todos estes objetivos foram pensados a partir da demanda dos alunos apresentada.

\section{CONTEÚDO E METODOLOGIA}

O projeto foi desenvolvido em três unidades: módulo 1 - Autoconhecimento e o Significado da Escolha Profissional; módulo 2 - Os Determinantes da Escolha Profissional; módulo 3 - Informação Profissional. Optou-se pela divisão em módulos para que os alunos pudessem compreender de forma abrangente a construção da abordagem histórico-cultural para a escolha profissional. Sendo assim, em primeiro lugar foi necessário compreender o que se entende por escolha profissional a partir desta visão, seguidos da importância de reconhecer a interferência de características identificatórias no processo de escolha e as informações profissionais que orientaram o que já será apreendido como opção profissional. 
O primeiro módulo visou introduzir a questão da escolha profissional discutindo os valores, a importância, a necessidade ou não desta opção para o sujeito, e como o processo de identificação, as "caras" das profissões, são construídos. Este módulo contou com três aulas. A primeira referiu-se à discussão de como se dá a constituição humana e a interferência das instâncias formativas apresentando a abordagem histórico-cultural. A segunda visou trabalhar com a discussão do período da adolescência como uma fase e não como um momento de crise, associando a necessidade do autoconhecimento e do projeto de vida no que se refere à escolha profissional. Por fim, a última aula deste módulo buscou fazer uma síntese de toda a discussão e de todos os conceitos apresentados através do debate do filme "Divergente" e da análise do conto “A profissão” de Isaac Asimov (1977).

O segundo módulo teve como objetivo apresentar os vários determinantes que compõem este processo de escolha e que muitas vezes não são identificados pelos alunos como fatores que influenciam na opção profissional. Este módulo conteve quatro aulas. A primeira refere-se à discussão do trabalho, abordando desde o conceito até o modo como ocorre na sociedade atual, desconstruindo vários ideais a respeito do tema. A segunda objetivou-se trabalhar com as interferências dos grupos sociais e de como a história pessoal foi formada a partir destes grupos. A terceira visou discutir o conhecimento das profissões e o papel da mídia como formadora de opiniões. Por último, a quarta aula pretendeu trazer a discussão dos estereótipos das profissões, de gênero e a questão do desempenho escolar neste processo de escolha.

Já o terceiro módulo, informação profissional, visou trazer informações a respeito das profissões através de profissionais e alunos da graduação de diferentes áreas. Além disso, houve uma elaboração de um trabalho final sintetizando todos os conteúdos trabalhados. Planejou-se em média quatro aulas para visitas de profissionais e graduandos das diferentes áreas que os alunos se interessaram até o momento, para que pudesse ser discutido como foi o processo de escolha e os determinantes presentes nela. $\mathrm{O}$ trabalho final teve como objetivo reunir os alunos em grupos para que cada grupo pudesse obter o máximo de informação sobre uma profissão, e assim apresentar para os alunos do primeiro ano do Ensino Médio, discutindo o processo de escolha e os seus determinantes.

A metodologia usada foi prioritariamente aulas expositivas dialogadas. Segundo Libâneo (1994), esta metodologia possibilita uma forma ativa entre o professor e os alunos, visando a obtenção de novos conhecimentos, habilidades, atitudes e convicções, assim como a 
fixação e consolidação de conhecimentos e convicções já adquiridos. Por serem aulas destinadas ao Ensino Médio, foi buscado o máximo de participação e envolvimento dos alunos, realizando em vários momentos ao decorrer da disciplina debates orientados (BECKER; BOBATO; SCHULZ, 2012).

\section{RESULTADOS E DISCUSSÃO}

Após a realização desta experiência foi possível fazer alguns apontamentos no que se refere ao trabalho com orientação profissional no Ensino Médio. Cabe salientar que propôs-se trabalhar a temática circunscrita à disciplina "Projeto de Vida", o que coloca a orientação profissional como um conteúdo e não como uma disciplina em si.

Observa-se que o Ensino Médio tem se efetivado na perspectiva de preparação dos estudantes para o ingresso no Ensino Superior e Mercado de Trabalho (KRAWCZYK, 2011). Tem-se, nesse sentido, a aplicação e direcionamento dos conteúdos curriculares para propiciar aprovação em processos seletivos que garantam tal ingresso. Percebe-se, inicialmente, que muitos estudantes e mesmo outros atores institucionais tinham uma expectativa de que o conteúdo de orientação profissional abordado por licenciandos de Psicologia se colocasse como decisivo no processo de escolha, atuando assim em consonância com a instrumentalização supracitada. Pode ser que tal anseio seja oriundo do conhecimento da atuação da Psicologia neste campo em contexto clínico. Em decorrência deste fator, na apresentação do projeto buscou-se localizar a Psicologia no espaço da escola e os objetivos da proposta. Avalia-se que esta apresentação foi fundamental aos alunos, aos professores e fundamentalmente aos licenciandos que só puderam fazê-la a partir de uma clareza conceitual e teórica que fora proporcionada pelo projeto construído.

A unidade "Autoconhecimento e Significado da Escolha Profissional", permitiu discutir o homem histórico-culturalmente constituído, que tem então todas as suas ações, inclusive o comportamento de escolha, como um processo adquirido. Tal conteúdo foi essencial para desconstruir noções como a de dons e de habilidades inatas, por vezes verbalizadas pelos estudantes. Ainda na unidade, a discussão da adolescência permitiu situar o processo de escolha profissional nesta etapa da vida, entendendo-o como uma exigência pessoal e social, com o fim de tornar os estudantes cidadãos produtivos. Foi um tema que suscitou muitos debates, haja vista que questões do mercado de trabalho, como: salário, status, 
prestígio social e outras se colocavam também como decisivas no processo de escolha de muitos estudantes.

Na unidade seguinte "Os Determinantes da Escolha Profissional", visou-se abordar de forma mais aprofundada as influências preponderantes (grupos sociais, história de vida, mídias e outros). Esta foi uma unidade em que não foi possível abordar todos os conteúdos previstos, em função do calendário escolar. De modo geral, pôde-se trabalhar com a noção de que há influências e que a identificação destas pode auxiliar no processo de escolha.

Nos debates com profissionais de diferentes áreas, que ocorreu na unidade seguinte: "Informação Profissional”, foi possível avaliar a apreensão dos conteúdos pelos estudantes, que fizeram perguntas consonantes com os conteúdos ministrados. Tinha-se o objetivo geral de que para além do conhecimento daquela profissão em si, os convidados falassem sobre a trajetória até a escolha e as consequências da mesma. Viu-se que tal objetivo foi alcançado, mesmo estudantes que não tinham interesse por uma área apresentada, participaram das discussões. É importante ponderar que no debate com os convidados abordou-se também as dificuldades para ingresso no ensino superior, especialmente no ensino público, a dificuldade em conciliar estudo e trabalho, além das dificuldades e impasses do processo de escolha e suas consequências.

O formato das aulas, em sua maioria, utilizando metodologia expositiva dialogada revelou-se como propícia aos conteúdos trabalhados e houve participação dos estudantes. Os resultados encontrados demonstraram a relevância em abordar orientação profissional no Ensino Médio, sendo este um conteúdo que propicia diálogo com outras disciplinas, em especial: sociologia, filosofia, história e literatura, o que está em acordo com as atuais propostas curriculares para o Ensino Médio, que apontam para a necessidade da interdisciplinaridade, conforme discute Ramos (2011), que aborda ainda o desafio da efetivação de tais propostas.

Considera-se que os objetivos foram alcançados, suscitaram-se algumas reflexões essenciais ao processo formativo. Os estudantes puderam pensar sobre os fatores que determinam a escolha profissional, situando as possibilidades sociais para sua realização, colocando em questão a realidade social que exige a escolha, mas por vezes limita sua realização.

\section{CONSIDERAÇÕES FINAIS}


Ao se ouvir a palavra "psicologia" quase sempre nos remetemos à clínica, ou mais especificamente, ao psicólogo. Isto se deve ao fato de que a licenciatura de Psicologia não é difundida como possibilidade de formação. Exatamente por isto, por vezes este campo fica carente de discussões e reflexões que possam embasar e desenvolver sua prática. Foi visando fomentar o debate em torno do professor de psicologia que este trabalho foi efetivado.

A primeira dificuldade encontrada é a falta do campo de atuação. Como a Psicologia não está inserida no Ensino Médio regular e o Magistério foi extinto do estado de Goiás (outra possível inserção do professor psicólogo) foi necessário inventar novos espaços para execução do trabalho. A escola de tempo integral - e seus diversos projetos complementares - foi a possibilidade vislumbrada por nós.

Após a inserção no colégio ocorreu ser necessário delimitar claramente nosso espaço: assim como foi dito acima, não poderíamos permitir a confusão entre a ciência Psicologia (enquanto campo abrangente e espaço de atuação dos psicólogos) e a Licenciatura em Psicologia. A Orientação Profissional passou a ser inserida no "Projeto de Vida" e assim discussões foram fomentadas, em formato de aulas, para possibilitar aos alunos melhor compreensão de todos os determinantes envolvidos no processo de escolha de uma profissão.

Por se tratar de um projeto complementar (e não como disciplina obrigatória) por vezes enfrentamos dificuldades como a falta de interesse dos alunos. Entretanto, tratando-se de um espaço de dupla formação (tanto para os alunos da educação básica quanto para os licenciados) fora possível abrir o diálogo e reformular as aulas, juntamente com os alunos do colégio, para que todos aproveitassem o máximo possível dessa experiência. As aulas expositivas dialogadas foram o melhor recurso encontrado para expor um conteúdo e fomentar discussões e debates ricos ao aprendizado.

Ao final, acreditamos que a experiência foi formativa, tendo em vista que os alunos conseguiram apreender as ideias que foram propostas por nós desde o início do projeto. Foi possível perceber a mudança nos paradigmas através da fala dos próprios alunos: passaram de fatalistas e naturalistas para uma compreensão que visa o todo e busca criticar aquilo que é imposto; analisar as multideterminações envolvidas em um processo de escolha; conhecer mais e melhor diversas profissões e o percurso necessário para se chegar até ela, etc.

Para os licenciados, a experiência também se mostrou extremamente formativa. Entrar em contato com a prática é algo que se faz necessário para efetivar a práxis, colocando em tensão o que é aprendido e a realidade, efetivando assim um espaço privilegiado de 
aprendizado. Além disso, aprende-se com cada aluno que entrara em contato conosco e, dessa forma, encontra-se ânimo para continuar com novos projetos e fomentar este campo que tanto necessita de investimentos: a educação.

\section{REFERÊNCIAS}

ABADE, F. L. Orientação Profissional no Brasil: uma revisão histórica. Revista Brasileira de Orientação Profissional. São Paulo, v.6, n. 1, p. 15- 24, 2005.

ANTUNES, M. Psicologia e Educação no Brasil: uma perspectiva histórica. In:. Anuário 2000: Psicologia: análise e crítica da prática educacional. [S.1.], $23^{\mathrm{a}}$ Reunião Anual da ANPEd, Caxambu, MG, 2000.

ASIMOV, I. A profissão. In: Nove amanhãs. Rio de Janeiro: Editora Expressão e Cultura, 1977.

BECKER, A. P. S.; BOBATO, S. T; SCHULZ, M. J. L. C. Meu lugar no mundo: relato de experiência com jovens em orientação profissional. Revista Brasileira de Orientação Profissional. São Paulo, v. 13, n.2, p. 253 - 263, 2012.

BOCK, A. M. B. Aventura do Barão de Münchhausen na psicologia. São Paulo: Educ/Cortez, 1999.

BOCK, S. D. Orientação profissional: a abordagem sócio-histórica. 3. ed. São Paulo: Cortez, 2006.

BRASIL. Conselho Federal de Educação. Resolução de no 5 de 15 de março de 2011. Disponível em: <http://www.abepsi.org.br/portal/?page $\mathrm{id}=741>$. Acesso em: 28 out. 2014.

FERRETI, C. J. Uma nova proposta de Orientação Profissional. São Paulo: Cortez, 1988.

FERRETTI, C. J. Uma nova proposta de Orientação profissional. 3. ed. São Paulo: Cortez, 1997.

CONSELHO REGIONAL DE PSICOLOGIA - $6^{\mathbf{a}}$ REGIÃO. Psicologia no Ensino de $\mathbf{2}^{\mathbf{o}}$ Grau: uma proposta emancipadora. São Paulo: EDICON, 1986.

KRAWCZYK, N. Reflexão sobre alguns desafios do ensino médio no Brasil hoje. Cadernos de Pesquisa, v. 41, n. 144, p. 752-769, set./dez. 2011.

LEVENFUS, R. S.; SOARES, P. H. P. (Org.). Orientação vocacional ocupacional: novos achados teóricos, técnicos e instrumentais para a clínica, a escola e a empresa. 2. ed. Porto Alegre: Artmed, 2000.

LISBOA, M. D. Orientação profissional e mundo do trabalho: reflexões sobre uma nova nova proposta frente a um novo cenário. In: LEVENFUS, R. S.; SOARES, P. H. P. (Orgs.). 
Orientação vocacional ocupacional: novos achados teóricos, técnicos e instrumentais para a clínica, a escola e a empresa. 2. ed. Porto Alegre: Artmed, 2000.

LIBÂNEO, J. C. Didática. São Paulo: Cortez, 1994.

PPP - Projeto Político Pedagógico do Colégio Estadual X, Cidade: SEE, 2014.

RAMOS, M. N. O currículo para o Ensino Médio em suas diferentes modalidades: concepções, propostas e problemas. Educação e Sociedade: Campinas, v. 32, n. 116, p. 771788, jul./set. 2011.

SPARTA, M. O desenvolvimento da orientação profissional no Brasil. Revista Brasileira de Orientação Profissional. São Paulo. v. 4, n. 1/2, p. 1-11, 2003.

PROGRAMA NOVO FUTURO; INSTITUTO DE CO-RESPONSABILIDADE PELA EDUCAÇÃO - Apostila de Aulas do Projeto de Vida, s/d.

VIGOTSKI, L. S. A Formação social da mente: o desenvolvimento dos processos psicológicos superiores. 4. ed. São Paulo: Martins Fontes, 1991. 